\title{
QUALITY OF COKE USED IN BLAST FURNACE PROCESS - ANALYSIS OF SELECTED PARAMETERS
}

doi: 10.2478/cqpi-2019-0081

Date of submission of the article to the Editor: 27/03/2019

Date of acceptance of the article by the Editor: 16/05/2019

Edyta Kardas ${ }^{1}$ - orcid id: 0000-0001-7699-2622

Pavlína Pustějovská ${ }^{2}$ - orcid id: 0000-0002-7073-3846

${ }^{1}$ Czestochowa University of Technology, Poland

${ }^{2}$ VŠB-Technical University of Ostrava, Czech Republic

\begin{abstract}
The basic economic goal of pig iron process is to produce a finished product at the highest possible quality and at the lowest possible cost. The quality of pig iron depends on the quality of raw materials used in the process, quality of fuels and process parameters. The cost of fuel is one of the basic component of cost of pig iron production. Therefore, consumption of fuels should be minimized while maintaining its high quality. The main technological fuel of this process is blast furnace coke. Very often, cheaper alternative kinds of fuels are used in the form of finer sorts of coke or alternative fuels (e.g. coal dust). However, they can be used only in a limited amount. The aim of the paper is the assessment of the selected quality parameters of stabilized coke used in the blast furnace process and the comparison of their values with requirements.
\end{abstract}

Keywords: blast furnace coke, qualitative parameters, qualitative analysis, composition of coke, Nippon Steel method

\section{INTRODUCTION}

Each company strives to obtain products with the best possible quality, the lowest possible cost and, at the same time, to meet the customers' requirements and achieve profits. Is should be remembered that the customer is not always interested in how specific production processes are going, or how the product is delivered to the place of sale, he is rather interested in the final effect expressed in the quality of product (Golebski et. al, 2019; Holota, 2016; Ulewicz, 2018). However, it is difficult to imagine the situation when the product quality could be designed without considering the forecasted, programed or planned processes that this product will be the subject throughout the entire life cycle (Sygut, 2018).

In the life cycle of each product, five basic phases, when quality is created, can be distinguish (Dziuba et. al, 2018): production preparation phase, production phase, distribution phase, operational phase and liquidation phase.

During the production phase, the following factors, that significantly affect the quality of products, are distinguished (Dziuba et. al, 2018): 
- Quality of work, determined on the basis of working conditions as well as the quality of contractors,

- Quality of materials: input raw materials, fuels and semi-finished products,

- Production quality: storage, placement of machines and equipment, transport and other.

So, it can be said that quality of fuels used in production processes is one of factors that affects the quality of product.

In blast furnace processes the use high-quality fuels, such as blast furnace (stabilized) coke, allows for optimal running the process, maintaining the parameters of its operation at optimal level. The use of cheaper sort of fuels at appropriate quantities can worsen the operation of the device and extend the time of melting and affect the chemical composition of the finished product (Kardas, 2019).

The article presents the part of the analysis of quality of coke used in blast furnace process. The aim of the paper is the assessment of the selected quality parameters of stabilized coke used in the blast furnace process and the comparison of their values with requirements. The analysis was made for the following parameters: content of moisture, volatile matter and ash in dry state, calorific value and CRI and CSR parameters of stabilized coke produced in one of Polish Coke Plants.

\section{CHARACTERISTICS OF COKE USED IN BLAST FURNACE PROCESS}

The main fuel for blast furnace process is stabilized coke. It plays triple function: technically as a fuel, chemical as a reducer and for carburizing of pig iron (carbon is a main element of coke) and mechanical as grate resistant to high temperatures (Niesler, 2012; Mianowski et. al, 2009). It is also the main factor responsible for costs of the process. Therefore, efforts should be made to minimize its use. However, it entails high requirements for the coke used in the process. Among others, ash content in coke has the great impact on coke properties. It also effects on (Lech et all, 2019):

- The quality of produced pig iron and the formation of slag,

- Cohesiveness of pieces of coke and, hence, its mechanical strength,

- The amount of added flux, what forces to increase the consumption of coke.

According to many authors, the quality of coke is determined in a multiparametric way, by determining the percentage of analytical component (moisture, ash), volatile matters and elements, and recently alkaline compounds. Next, physical properties such as density, porosity, grain composition are evaluated and the characteristics of coke is completed by the broad possibilities of testing its mechanical properties, such as strength and abrasiveness. Sometimes its heating value is additionally determined. In addition, two parameters for CRI and CSR coke are also assessed (Mianowski et all, 2009; Niesler, 2012; Zieliński, 1986).

In the tested blast furnace, a blend of cokes of various granularity and different physic-chemical properties is used. Their basic characteristics according to Polish standard are presented in Table 1.

In addition to stabilized coke, also other fuels in the form of finer sorts of coke are used, e.g. breeze coke that significantly reduces the cost of coke (Table 1), coal dust and small amount coke-oven gas and natural gas. During production process also blast furnace gas is used to heat the blast. These fuels are used to reduce total production costs of pig iron (Bernasowski et. al, 2014). 
Table 1

Characteristics of coke according to PN-86/C-02050.06

\begin{tabular}{|c|c|c|c|c|}
\hline \multirow[t]{2}{*}{ Properties } & \multicolumn{4}{|c|}{$\begin{array}{l}\text { Required values for individual coke } \\
\text { assortments }\end{array}$} \\
\hline & Stabilized & Nut coke & Pea coke & $\begin{array}{l}\text { Breeze } \\
\text { coke }\end{array}$ \\
\hline Grain dimensions, $\mathrm{mm}$ & $25-80$ & $20-40$ & $10-25$ & $0-10$ \\
\hline Ash content in dry state, \% - max. & 10.5 & 11.0 & 11.0 & 13.0 \\
\hline S content in dry state, $\%$ - max. & 0.8 & 1.1 & 1.2 & 0.8 \\
\hline Moisture content, \% & 5.0 & 12.0 & 16.0 & 17.0 \\
\hline $\begin{array}{l}\text { Volatile matter content in dry state, \% - } \\
\text { max. }\end{array}$ & 1.1 & 1.2 & 1.4 & 2.0 \\
\hline Calorific value, kJ/kg (approx.) & 29500 & 29500 & 29500 & 28500 \\
\hline $\begin{array}{l}\text { Drum strength: } M_{25}, \%-\min . \\
M_{10}, \% \text { - max. }\end{array}$ & $\begin{array}{l}85 \\
7\end{array}$ & - & - & - \\
\hline Oversize content, \% - max. & 6 & - & - & - \\
\hline Undersize content, \% - max. & 6 & - & - & - \\
\hline Content of grain $80-40 \mathrm{~mm}, \%$ - min. & 65 & - & - & - \\
\hline
\end{tabular}

Source: (PN-86/C-02050.06, 1986)

\section{CHARACTERISTICS OF ANALYZED COKE}

Blast Furnace Department under study uses different sorts of coke. Quality analysis was made for stabilized coke produced in Polish Coke Plant. Content of elements in coke and chemical composition of ash for one selected month are presented in Table 2 and 3.

Table 2

Content of main substance of blast furnace coke

\begin{tabular}{|l|c|l|l|l|}
\hline \multirow{2}{*}{$\mathbf{H}_{2} \mathrm{O}, \%$} & \multicolumn{4}{|c|}{ Content in dry state of coke } \\
\cline { 2 - 5 } & $\mathrm{S}, \%$ & Ctotal, \% Volatile matter, \% & Ash, \% \\
\hline 5.93 & 0.493 & 88.83 & 0.57 & 10.20 \\
\hline
\end{tabular}

Source: (Information materials, 2018).

Table 3

Chemical composition of ash in blast furnace coke

\begin{tabular}{|l|c|l|l|l|l|l|l|l|l|c|c|}
\hline $\mathbf{F e}, \%$ & $\mathbf{S i O}_{2}$ & $\mathbf{C a O}$ & $\mathbf{M g O}$ & $\mathbf{A l}_{2} \mathbf{O}_{3}$ & $\mathbf{M n}$ & $\mathbf{P}_{2} \mathbf{O}_{5}$ & $\mathbf{N a}_{2} \mathbf{O}$ & $\mathbf{K}_{2} \mathbf{O}$ & $\mathbf{Z n}$ & $\mathbf{S}$ & $\mathbf{P b}$ \\
\hline 6.84 & 50.84 & 4.55 & 1.66 & 26.00 & 0.19 & 0.96 & 1.44 & 1.57 & 0.02 & 0.422 & 0.007 \\
\hline
\end{tabular}
Source: (Information materials, 2018).

As it can be seen in Table 2 and 3 it can be said that the analyzed coke content of main substances is similar to required value. Moisture content was a bit higher than required value, but ash content and volatile matter did not exceeded requirements.

\section{METHODOLOGY OF THE ANALYSIS}

Quantitative analysis of selected parameters of stabilized coke was made. The content of moisture, the content of volatile matter and ash in dry state, calorific value was taken into account in the first part of the analysis. Next, CRI and CSR indicators determined according to the Nippon Steel method was analyzed. The changes in all parameters during analyzed period of time were made using cards of variation of parameters. Monthly values of parameters were compared to the average and limit 
values. Next, the relation between $\mathrm{CRI}$ and CSR parameters was determined using linear regression method. The analysis covers the time of one calendar year. The results were gathered in Blast Furnace Department which is a part of one of the biggest Steel Plant in Poland.

\section{THE ANALYSIS OF SELECTED QUALITATIVE PARAMETERS}

The analysis of selected quantitative parameters was made. First part of the analysis the content of elements: moisture, volatile matter ash and calorific value was made. Limited values were defined according to the requirement of Blast Furnace Department: moisture - max. 5\%, volatile - max. $1.1 \%$ and ash $-11.5 \%$. The results of the analysis are presented in Figure 1-4.

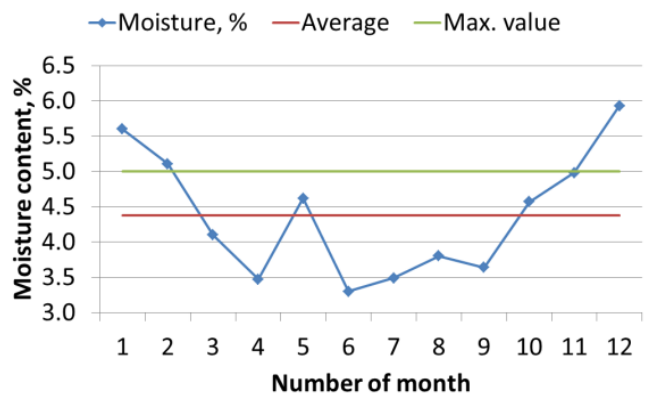

Fig. 1. Analysis of moisture content of blast furnace coke in the study period Source: (Information materials, 2018)

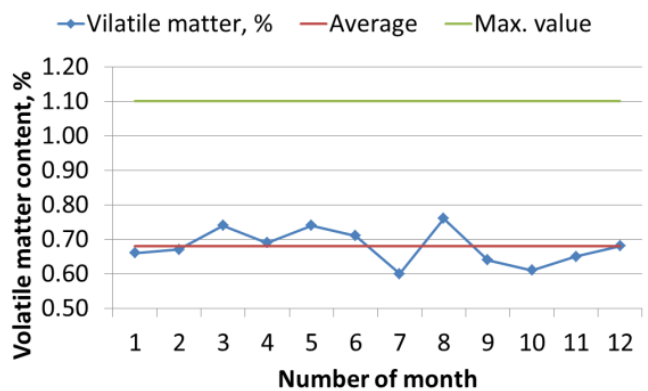

Fig. 2. Analysis of volatile matter content of blast furnace coke in the study period Source: (Information materials, 2018)

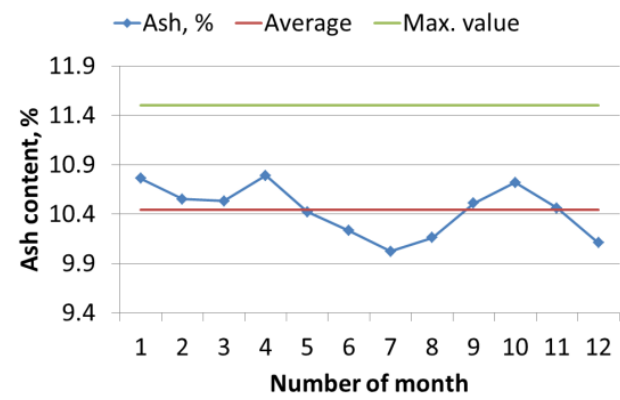

Fig. 3. Analysis of ash content of blast furnace coke in the study period Source: (Information materials, 2018)

Based on results presented in Figure 1 it can be said that average moisture content in coke was on the level of $4.4 \%$ what is much lower than maximum value $(5 \%)$. The 
highest values were noticed at the beginning and at the end of the calendar year, while the lowest - during summer month. It is caused by seasoning of materials and fuels. All materials and fuels are collected in special landfills outside, so weather conditions have a significant impact on them (especially air moisture).

Results of the analysis presented in Figure 2 shows that during the study period volatile matter content in coke is much lower than maximum value $(1.1 \%)$. Values of the parameter in separate months fluctuated only slightly. The lowest value was noticed in month $7(0.60 \%)$ and $10(0.61 \%)$, while the highest - in month $8(0.76 \%)$.

Based on the results presented in Figure 3 it can be said the maximum value of ash content of coke was not exceeded. The average content was on the level of $10.44 \%$ and there was no big difference between individual values. The lowest values were noticed in the middle of study period (month 6-8) and in month 12, the highest values - on the beginning of the analyzed year.

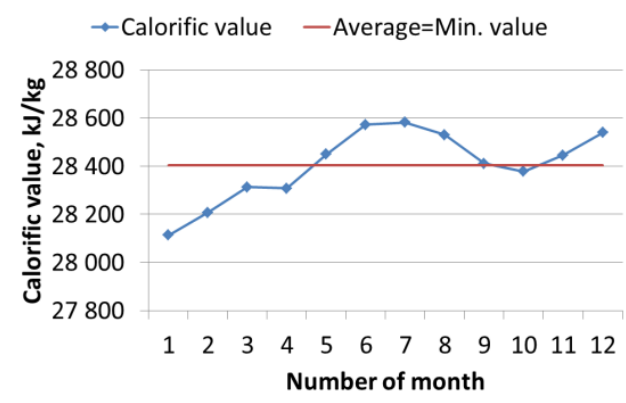

Fig. 4. Analysis of calorific value of blast furnace coke in the study period Source: (Information materials, 2018).

According to the results presented in Figure 4 it can be said that average calorific value during the whole year was $24803 \mathrm{~kJ} / \mathrm{kg}$ of coke, what is on the level of minimum value $(28400 \mathrm{~kJ} / \mathrm{kg}$ of coke). The lowest values of the parameter (under the minimum value) were noticed on the beginning of the year and in month 10 . It was mainly caused by economic reason.

Two coke properties were selected for the quantitative analysis: its reactivity and mechanical strength. One of ways to determine these values is the method developed by Nippon Steel Corporation and normalized in Polish Standard (PN-C-04312:1996). The CRI (coke reactivity index) is based on gasification of $200 \mathrm{~g}$ of a coke sample with the grain size of $20 \pm 1 \mathrm{~mm}$ in a $\mathrm{CO}_{2}$ stream at a temperature of $1373 \mathrm{~K}$ and determination of percentage loss in its mass. The coke strength after reaction CSR (coke strength after reaction) is determined on a previously gasified sample by tumbling it and then evaluating the mass of grains that after tumbling have retained the dimensions above $10 \mathrm{~mm}$. The purpose of this method is determination of reactivity and strength of coke in conditions as close as possible to the conditions in blast furnace (Konstanciak, 2013; Konstanciak, 2015). These parameters are calculated according to the following formulas (Zieliński, 1986):

where:

$$
C R I=\frac{m_{1}-m_{2}}{m_{1}} \cdot 100 \%
$$

$m_{1}$ - mass of coke sample before reactivity determination, $\mathrm{g}$,

$\mathrm{m}_{2}$ - mass of coke sample after reactivity determination, $\mathrm{g}$, 
where:

$$
C S R=\frac{m_{3}}{m_{2}} \cdot 100 \%
$$

$\mathrm{m}_{3}-$ mass of coke with grain size above $10 \mathrm{~mm}$ after tumbling, $\mathrm{g}$.

The results of the analysis of $\mathrm{CRI}$ and CSR parameters are presented in Figures 5 and 6.

According to the results of $\mathrm{CRI}$ parameter presented in Figure 5 it can be said that average value of $\mathrm{CRI}$ parameter was on the level of $27.62 \%$ that was lower than maximum value (28\%). However, in some months this value was exceeded: in first half of tested year and month 8 , then the value decreased. In month 11 value of CRI was the lowest $(26.12 \%)$. It must be underlined that the deviation of this parameter was low, app. $2.5 \%$ of average value.

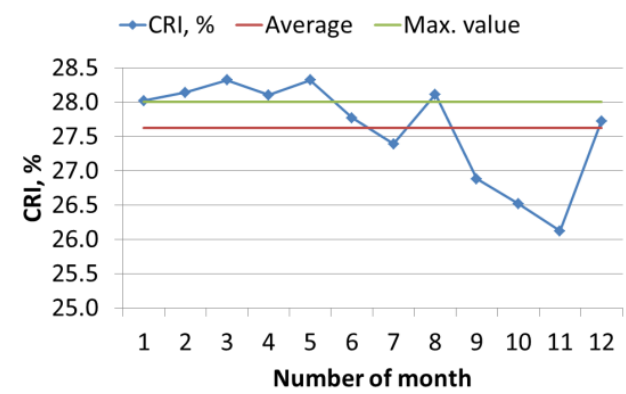

Fig. 5. Analysis of CRI parameter of blast furnace coke in the study period Source: (Information materials, 2018).

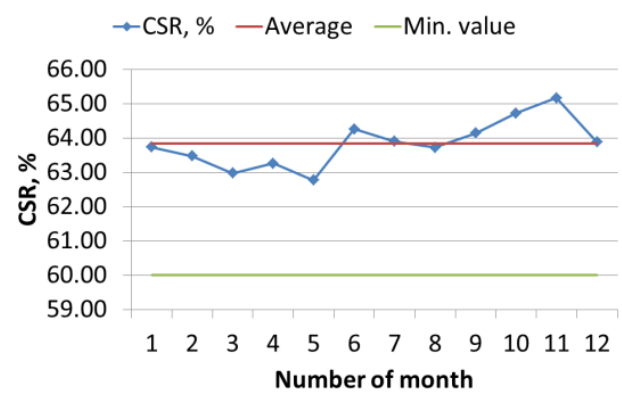

Fig. 6. Analysis of CSR parameter of blast furnace coke in the study period Source: (Information materials, 2018).

Based on the results of the CRS parameter presented in Figure 6 it can be seen that during the whole analyzed period of time value of CRS parameter was much higher than minimum value $(60 \%)$. The average value of the parameter was on the level of $63.83 \%$. At the beginning of the analyzed time the value of the parameter was lower than the average, then it started to decrease, the highest value was in month 11 (65.17\%). The situation is opposite to CRI parameter, what confirms the dependence between parameters (Niesler, 2012).

The relation between $\mathrm{CRI}$ and CSR parameters was determined. The results of the analysis are shown in Figure 7 and Table 4. According to the results it can be concluded that CRI parameter was ranged between the values 26.12 and $28.32 \%$, while CSR parameter -62.77 and $65.17 \%$. The regression function shows that the increase the CRI parameter by $1 \%$ resulted in decreasing CSR parameter by app. $0.84 \%$. Auxiliary calculations (standard error less than $0.5 \%$ of the studied 
phenomenon, significance of the model explanatory variable) show a good fit of the regression function to the empirical data.

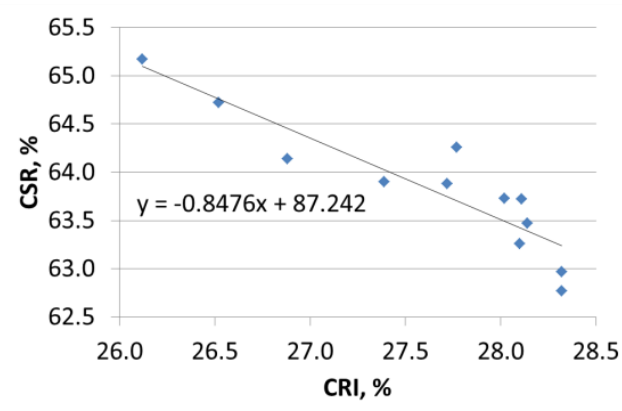

Fig. 7. CSR parameter vs. CRI parameter of blast furnace coke Source: (Information materials, 2018).

Table 4

Auxiliary calculations for the regression function, describing the CSR dependence on the CRI

\begin{tabular}{|c|c|c|}
\hline Se & \multicolumn{2}{|c|}{0.3039} \\
\hline Ve & \multicolumn{2}{|c|}{$0.47 \%$} \\
\hline$d(a)=0.1243$ & $\mathrm{t}(\mathrm{a})=-6.81$ & $\mathrm{p}(\mathrm{a})=4.65 \cdot 10^{-5}$ \\
\hline $\mathrm{d}(\mathrm{b})=3.4353$ & $\mathrm{t}(\mathrm{b})=25.3954$ & $\mathrm{p}(\mathrm{b})=2.06 \cdot 10^{-10}$ \\
\hline
\end{tabular}

Source: (Information materials, 2018).

\section{CONCLUSION}

One of the basic economic goal of blast furnace process is the production of pig iron that has appropriate quality parameters values and the lowest possible costs. The main factor determining the total cost of production is the cost of main fuel, highquality stabilized coke. There is a tendency to reduce its consumption by the use of cheaper coke assortments or alternative fuels (e.g. injection of coal dust). The use of such fuels is possible, but only in limited quantities, due to the tasks that coke performs in the blast furnace. The replacement, therefore, forces the stabilized coke to maintain optimal values of mechanical properties.

The results of the analysis presented in the paper showed the changes of selected quality parameters of stabilized coke in the analyzed period of time and indicated the periodic exceeding of limit values in a few cases:

- In the analyzed period of time, the limit value for moisture content in coke was exceeded. However, it should be taken into account that all raw materials used in the blast furnace process, including coke, are stored on external landfills specially prepared for this purpose. Therefore, the atmospheric conditions had a major influence on the values of this parameter. Exceeding the limit value took a place at the beginning and end of the study period, so low temperatures and rainfalls could affect the moisture content.

- In case of content of volatile matter and ash in dry state of coke, there was no exceedance of limit values, and it should be also noticed that parameters were only under small variability in the entire study period.

- For calorific value, the average value of this parameter was equal to the recommended minimum value for this assortment of coke. Lower parameter values were recorded primarily at the beginning of the research period of time. The use of coke with exceeded minimum calorific value was mainly due to economic reasons and the signed contract with the supplier of this fuel. 
- In case of CRI and CSR parameters, similarly as in case of calorific value, the recommended values of these parameters were exceeded at the beginning of the study period. However, the differences were no significant. The use of this coke was caused primarily by economic considerations.

Therefore, it can be concluded that the tested stabilized coke was of satisfactory quality. Periodical use of coke with exceeded recommended values of some parameters was dictated mainly by the economic aspect. In case of slight decrease of quality of coke, the deterioration of condition of blast furnace process were also noted. However, this changes were small and did not increase the production costs.

\section{REFERENCES}

Bernasowski, M., Ledzki, A., Stachura, R., Klimczyk, A., 2014. Basic Structure Of The Fuel Rate Optimization Model And Its Practical Use At The Blast Furnace Technology. 23th International Conference On Metallurgy And Materials, Brno, Tanger, 39-44.

Dziuba, S.T., Ingaldi, M., Kadlubek, M., 2018. Quality analysis of the steel bars in chosen metallurgical enterprise. 27th International Conference On Metallurgy And Materials, Brno, Tanger, 1893-1898

Gołębski, R., Sikora, P., Gnatowski, A., 2019. The Use of New Technology to Improve The Quality of Production on a CNC Machine Tool. CzOTO, 1, 1, 583-590.

Holota, T., Hrubec, J., Kotus, M., Holiencinova, M., Caposova, E., 2016. The Management Of Quality Costs Analysis Model. Serbian Journal Of Management, $11,1,119-127$.

Information materials, 2018. Blast Furnace Department of Steelworks X.

Kardas, E., 2019. Statistical Analysis Of Quality Parameters Of Pig Iron. CzOTO, 1, 1, 616-623

Lech, K., Jursova, S., Kobel, P., Pustejovska, P., Bilik, J., Figiel, A., Romański, L., 2018. The relation between CRI, CSR indexes, chemical composition and physical parameters of commercial metallurgical cokes. Ironmaking and Steelmaking, 46, 2, 124-132

Konstanciak A., 2013, The effect of blast furnace coke quality on the possibility of its use. Metalurgija, 52, 2, 193-196.

Konstanciak, A., 2015. Evaluation of the quality of coke for blast furnace process in chosen metallurgical plant. METAL: 24th International Conference On Metallurgy And Materials, Brno, Tanger, 1988-1993.

Mianowski, A., Radko, T., Karkoszek, A., 2009. Assessment of the high-quality blast furnace coke by using the reactivity and strength integrated Nippon Steel Corporation test. Chemical industry, 88, 6, 692-698.

Niesler, M., 2012. The role of coke grain in the blast furnace process. Institute of Ferrous Metallurgy, Gliwice.

PN-C-04312:1996. Hard coal coke - Determination of reactivity towards carbon dioxide and strength after reactivity.

PN-86/C-02050.06, 1986. Hard coal coke - Industrial and heating coke.

Sygut, P., 2018. Control of incompatibilities in the production of helmets for mining. MATEC Web of Conferences, 183, 03002.

Ulewicz, R., 2018. Outsorcing quality control in the automotive industry. MATEC Web of Conferences, 183, 03001.

Zieliński, H. (Ed.), 1986. Cokemaking. Publishing House Slask, Katowice. 